Since detailed descriptions of the scientific work in progress at the various research institutes aided by the Development Fund are published elsewhere, only a brief outline of their work is given in the present report. The scheme, organised by the Society of Friends, for assisting unemployed men in cultivating allotments, was once again given financial support, in view of the great success of the work in 1933 . Disappointment, however, is expressed that it was not possible to assist as many as had been hoped, chiefly owing to the difficulty in securing suitable land. The Rural Economy Section reports progress on nearly all sides, and rural industries are being developed over most of Great Britain on practical and profitable lines. Fishery research has also produced valuable results, particularly with regard to the herring and haddock industries. The determination of the best-sized mesh to use to ensure that undersized fish are not landed has enabled definite legal regulations to be enacted, and the survey of young haddock stock has rendered it possible to forecast the quantities of marketable fish and their probable distribution in future years. The report concludes with a financial statement and a schedule of the grants allocated during the year under review.

\section{Agricultural Research in East Africa}

THE Colonial Office has issued the sixth annual report (1933-34) of the East African Research Station at Amani (London : H.M. Stationery Office. 1s. net), from which it is evident that progress has again been made in all the various research activities with which the Station is concerned. As regards coffee investigations, the earlier impression that heavy applications of organic manures to arabica coffee effectively offsets the harmful influence of soil acidity has now been confirmed, while culture solution studies suggest a marked correlation between acidity of the medium and the degree of branching of the roots which occurs, high acidity being associated with an unbranched type of root system. Results of importance have also been obtained by the plant pathology section, as the vector of the mosaic disease of Cassava has been definitely proved to be a species of white fly (Aleurodidce). On the biochemical side comes the discovery that the fermentation of coffee is an unnecessary process so far as quality is concerned, though the difficulties of correlating quality with the method of preparation of the coffee are still not overeome. The cultivation of sisal (Agave amaniensis) continues to increase, and the first lot of seedlings raised at the research station are now becoming available for fibre tests, the standardisation of which has been considerably developed during the past year.

\section{Fishery Research in the U.S.S.R.}

THE organisation of fishery research in the U.S.S.R. is the subject of a brief but highly important article by Prof. B. S. Ilyin in the current issue of the Journal du Conseil (9, No. 3. Conseil Permanent International pour l'Exploration de la Mer. Andr. Fred Høst et Fils, Copenhague. December 1934). The Scientific Institute of Marine Fisheries, formerly the
Central Scientific Institute of Fisheries (Moscow), and the State Institute of Oceanography (Moscow) have been united under the name of the "Union Scientific Institute of Marine Fisheries and Oceanography". The new Institute is designed to function as a planning, guiding and co-ordinating centre for the activities of the numerous fishery stations situated around the coasts of the U.S.S.R. Its purpose is to promote the welfare of the fisheries by acquiring data concerning marine biological and oceanographical phenomena, and intelligently applying the results. In this connexion the formation of an economic section is of especial interest and importance in view of present events and tendencies in the fishing industry of Great Britain. The Institute will issue three series of publications-Transactions, Records and Bulletins-all in Russian, but the first two will be furnished with English, French or German sum. maries. The address of the Institute is Moscow, Verkhne Krasnoselskaya 17.

\section{Research in the Electrical Industry}

THE fourteenth annual report of the British Electrical and Allied Industries Research Association (the E.R.A.) shows that the electrical industry is fully alive to the commercial value of research. It has been well supported both by the Government and the various branches of the industry during last year, and although we do not agree that there can never be a point "at which research has all the support it needs and deserves", it has certainly not been "oversubscribed" in the past. The long list of researches the Association has before it, still inadequately financed, shows that there is need for further co-operative help. It is interesting to read that designers of insulating material for electrical material are now attaching less importance to a knowledge of the electric strength of their materials and more to their thermal conductivity. The importance of Fourier's theorems on the conduction of heat is being fully recognised, and also that temperature is a leading factor in electrical breakdowns. For some years the flame of the Méker burner has been the standard for the determination of "resistance to naked flame". It has been found that the standard. isation of the burner flame in conjunction with simple correction factors is unsatisfactory, as flame tem. perature is not correlated to the calorific value of the gas in a simple manner. Further experiments are being made to develop a standard flame for scientific tests in connexion with 'inflammability'. The electrical resistivity map of the soil of England and southern Scotland has now been completed, and a summary of the work done on telephone interference has been published. Tests on radio interference are in progress. A list is given of the Government departments, engineering and scientific institutions, universities and colleges which have co-operated in the work of the Association.

\section{Progress in Radio Communication}

A paper by Col. A. S. Angwin giving a review of the progress of radio communication for the year 
1934 (J. Inst. Elec. Eng., Feb. 1935) is of general interest. The great technical progress made in broadcasting during the last two years is reflected in its rapid development. At the beginning of 1932, the number of licensed listeners in Europe was nearly 14 millions, and two years later it was nearly 20 millions. In 1929 the total power used in broadcasting was 420 kilowatts, whilst five years later it was more than ten times greater. Now that an average high-power station consumes 2 million electric units a year, it is important to use only transmitters of high efficiency. The extended use of short-wave telegraph working in ships has enabled the British P.O. stations to communicate regularly with whaling boats in the antarctic and in eastern waters. Directive aerials have been erected at these stations covering all the main shipping routes of the world, and this has greatly improved the services. Additional radio-telephone services from Great Britain to South Africa, Egypt and India have been opened up, while services to Japan, Shanghai, Kenya and Iceland are projected. By extension to circuits already existing, radio communication is now possible with nearly all the South American States. The outstanding feature in radio research has been the intensive study with the help of the cathode ray oscillograph of the propagation of waves in the ionosphere. The methods now in use indicate that the reflected signal resulting from a single pulse incident on the ionosphere consists frequently of a doublet the components of which are separated by a small time-interval. The reflected components are apparently electrically polarised waves of opposite rotational sense.

\section{Machine Mining and Labour Problems}

Authougr machine mining has made comparatively rapid progress during recent years, there is still room for a great advance in mechanisation. In a paper by Mr. J. Dooley, printed in the Mining Electrical Engineer of February, it is stated that in Yorkshire, which is one of the most progressive coal fields of Great Britain, only about one third of the coal produced is cut by machines and only about a sixth is loaded on to conveyor belts. There are a few coal seams from which coal simply rolls over into the 'tub', and it would be quite unnecessary to 'machine-cut' the faces of these seams. But even in these cases mechanical loading could be economic. ally applied by means of conveyors of suitable design. Another economic factor which has to be taken into account is the possibility of a shortage of suitable labour in the near future. This question may rapidly become acute as newer and more attractive industries and interests arise to attract the boys and young men who would otherwise automatically enter the pits. It is true that to some extent machines displace labour temporarily, yet the position may be reversed, and collieries be compelled to put in machines because sufficient labour is not available. It is essential for colliery managers to get to work with new ideas, and arrange and organise systems of work so that full advantage be taken of the existing types of machinery. There are machines already in use designed to carry enormous loads in supporting the roof and protecting other machines employed for cutting, loading and conveying coal simultaneously. American collieries have very large outputs per 'man shift', far in advance of anything ever attempted in Great Britain.

\section{Pacific Science Association}

THe Fifth Pacific Science Congress of the Pacific Science Association was held in Canada in 1933 under the presidency of Dr. H. M. Tory, president of the National Research Council of Canada. The Congress, which was held under the auspices of the National Research Council of Canada and through the generosity of the Government of Canada, was a notable achievement in the history of the Association. Representatives of no less than thirty-two countries attended the Congress, while the total number taking part in the meetings exceeded four hundred. The meetings were held in Victoria, B.C., on June 1-4 and in Vancouver, B.C., on June 5-14. The success of the Congress has now been crowned by the pub. lication of the Proceedings in five large volumes amounting to more than four thousand pages (Toronto : University of Toronto Press; London : Oxford University Press, 1934. 5 vols. 84s. net). These volumes form a noteworthy summary of scientific knowledge from many aspects contributed by research workers of those countries bordering the Pacific Ocean. It is clearly not possible to review the contents of these volumes, but mention should be made of the lavish hospitality extended to the members and participants by the Canadian authorities. The many social functions and the interesting excursions arranged for the entertainment of the visitors must have largely fulfilled one of the main objects of the Pacific Science Association, which is "to strengthen the bonds of peace among Pacific peoples by promoting a feeling of brotherhood among the scientists of all the Pacific countries". This alone should be sufficient tribute to the devoted care and energy given by those responsible for the organisation of the Congress.

\section{German Science}

A NEW quarterly review in English of German science has appeared under the title "Research and Progress" (Terramare Office, Berlin W.8), the editor being Dr. Karl Kerkhof. In the second number, which appeared in April, the articles are mostly geographical or cultural and historical in character. Prof. Erich von Drygalski discusses the effect of the polar regions on the history of the earth, dealing with the influence of currents of air from the pole from the physical, biological and human points of view, while Prof. Rudolf Spitaler considers the influence of shifts in the earth's axis on the production of earthquakes. Prof. Diedrich Westermann deals with a subject on which he has already made his views familiar to English readers - the changing African. The introduction of syphilis from the New World in 1493 is characterised by Prof. K. Sudhoff as a legend; it is suggested, however, that it may have spread by earlier contacts between the old 